\title{
ESTIMATING THE EFFECT OF BIOFUEL ON LAND COVER CHANGE USING MULTI- YEAR MODIS LAND COVER DATA
}

\author{
Nagendra Singh and Budhendra L. Bhaduri \\ Computational Science and Engineering Division, Oak Ridge National Laboratory \\ P.O. Box 2008, MS 6017, Oak Ridge, TN 37831-6017 \\ singhn@ornl.gov,bhaduribl@ornl.gov
}

\begin{abstract}
There has been a growing debate on the effects of the increase in demands of biofuels on land use land cover (LULC) change with apprehension in some quarters that the growing demand forf bioenergy as a clean fuel will result in widespread direct and indirect LULC change. However estimating both direct and indirect LULC change is challenging and will require development of accurate high frequency, high resolution (temporal and spatial) land use land cover data as well as new LULC models which can be used to locate, quantify and predict these changes. To assess whether the demand for biofuel has caused LULC we used MODIS land cover data (MCD12Q1) from 2001 to 2008 along with cropland data layer (CDL) to estimate cropland and grassland changes in United States for the years 20022008 as well as its correlation with biofuel growth.
\end{abstract}

Index Terms-Biofuel, LULC, MODIS, Cropland,

\section{INTRODUCTION}

The causes and effects of land use land cover (LULC) change has been a topic of interest amongst researchers $[1,2,3]$. Traditionally urbanization and population growth were considered to be one of the main drivers of LULC changes. However recently projected LULC change due to the growing demands of biofuel has been in the spotlight. Researchers have shown that widespread conversion of forestland and grassland to cropland will offset the reduction in carbon emission which was expected to reduce due to biofuels [4,5] replacing fossil fuels [5,6]. Cropland is one land class which is expected to be affected by the expansion by biofuels both in terms of land use and land cover. To meet the demands of bioenery existing cropland like wheat, soybean are likely to be converted into corn while existing land cover like grassland and forestland could be cleared to plant new bioenergy crops. Cropland in the US has either decreased or has remained constant in most states in the past 50 years [7].Prior to 1950 most of the cropland in the US expanded by clearing forest, steppes and grassland and it is estimated that the largest portion of cropland was created by clearing about 1 million $\mathrm{km}^{2}$ of grassland in North America [8].In their study Searchinger et al.[6] estimate that to meet the requirements of biofuel in the US about 0.1 million $\mathrm{km}^{2}$ additional cropland would be needed globally out of which 0.02 million $\mathrm{km}^{2}$ will come from the US. We use MODIS[9] land cover data and Cropland Data(CDL) Layer [10] from 2001 to 2008 to estimate cropland changes in US for the years 2002-2008 and estimate the area of grassland converted to cropland for this time period. These two classes were chosen as they are separate distinct classes in the MODIS dataset and it is expected that widespread conversion of grassland to cropland will occur to meet the demands of biofuel. We also estimate for the state of Nebraska how much of this change has been due to corn and whether there is any correlation between these changes and land use changes.

\section{METHODOLOGY}

MODIS land cover data (approx $500 \mathrm{~m}$ resolution for the years 2001-2008 was used to estimate the amount of cropland being converted to grassland. We used two classes cropland (class 12) and grassland (10) from the IGBP classified data for this study, a detailed description of these classes can be found in Friedl et al [8]. The 17 classes of the land cover were reclassified into 3 classes namely cropland (class12), grassland (class 10) and all the other classes were combined into one class as 'others'. Analysis of data from 2001-2008 was used to estimate how these three land cover classes had changed from year to year. Six possible changes i.e. grassland being converted to cropland, cropland converted into grassland, and both these classes being converted into other classes and vice versa were analyzed.. Data from CDL was used to estimate how much of the replaced grassland was being used for corn cultivation. We used data for the state of Nebraska for our analysis because it showed an increase in cropland from 2005 onwards, in addition calculations showed that it is one of the states where the highest amount of grassland was being converted to cropland. To estimate how much of the replaced grassland was used by corn the land cover change data obtained by analysis of MODIS land cover was reclassified into binary raster's. All the cells which changed from grassland to cropland were classified as 1 and all the others cells were classified as 0 . This reclassified raster was then multiplied by the CDL data for state of Nebraska for each 
year which resulted in a raster having data only in those areas where grassland was converted cropland. The area of these rasters was aggregated at the county level for each year and used in subsequent analysis.

\section{RESULTS}

To estimate how well the MODIS land cover class cropland corresponds with cropland as estimated by the census of agriculture (http://www.agcensus.usda.gov) county level cropland estimates from the 2002 and 2007 census of agriculture were compared with that of the MODIS land cover data for 2002 and 2007. There is a strong linear correlation between both the estimates with a correlation coefficient value of .82. On the other hand year 2007 shows a slightly lower correlation coefficient of .80. Considering data for 3111 counties was used we assume that the estimates from MODIS land cover are a good estimate of cropland in the US (.80 to .83 $95 \%$ confidence interval for 2002 and .79 to. $8195 \%$ confidence interval for 2007). Total cropland area in the US has decreased from 20012008 by around 0.08 million $\mathrm{km}^{2}$ as calculated from the MODIS data, this is very similar to the cropland change of around 0.1 million $\mathrm{km}^{2}$ as estimated by the Census of Agriculture from 2002-2007. Cropland area in general decreased in most states across US from 2001-2008 though occasionally some states showed an increase. Of all the major crop producing states South Dakota and Nebraska are the two states which show an increase in cropland of around $4 \%$ from 2005 onward. Overall the amount of cropland converted to grassland is much higher compared to grassland converted to cropland except for the years 2002 and 2007 when the amount of grassland converted to cropland was higher. Figures 3 show the spatial distribution of areas where grassland has been replaced by cropland for the years 2002-2008. For 2002-2004 Nebraska and Kansas are two states of the corn belt where over $100 \mathrm{~km}^{2}$ of grassland was replaced by cropland, most of other changes occur in the western part of the country. In the year 2005 an increase in the conversion of grassland to cropland was observed in the states of Kansas, Nebraska, South Dakota and North .In 2006 the conversion reduced significantly (around $40 \%$ ) and was concentrated mostly in the northwestern part of the country i.e. the states of Oregon, Idaho, Montana and Nebraska. Amongst the states with high cropland area Kansas, Nebraska, South Dakota and Texas showed conversion of over $100 \mathrm{~km}^{2}$ of grassland being converted to cropland for 2002-2008 while some of the other major corn producing states like Iowa, Illinois, Minnesota and Indiana hardly showed any such conversions. Nebraska recorded relatively higher proportion of conversion of grassland to cropland in comparison to other states and being one of highest corn producer in country it was further analyzed to see how much of the converted area is being used for corn production and whether there is any correlation between conversion and biofuels. The replacement of grassland by corn in Nebraska has been generally constant from 2001-2008. The percentage of grassland replaced by corn was around $28 \%$ for 2002-2003 and since then has been constant at around $16 \%$ since 2004 with a decrease of $11 \%$ in 2007 . The correlation between replaced grassland and planted corn at the county level for Nebraska is shown in figure 2 and it can be seen that the correlation decreases gradually from 2002-2008.

\section{DISCUSSIONS AND CONCLUSION}

Area of cropland has decreased in the US from 2001 to 2008 with an average rate of around $1 \%$ every year however in between cropland area increased by $3 \%$ from 2004 to 2005 and then again decreased by $1.4 \%$ from 2005 2006, remained constant from 2006-2007 and then decreased by around $1 \%$ in 2008 . Even though 7 years (2001-2008) is not long time period for monitoring trend the data gives a good indication on how cropland could have been affected by demand in biofuel as it covers a time period both before and after the production of biofuel started rising which is around 2004-2005. There is no positive correlation between increase in biofuel and cropland over this time period in fact there is a negative correlation of 0.6 between the two (though the result is not statistically significant at $95 \% \mathrm{CI}$ ). Analyzing data for smaller periods may show some correlation but it will not show the correct trend. For example if one were to use data from 2003 to 2005 they would come to the conclusion that cropland area is increasing with the production of biofuel in the US. In addition there are uncertainties associated with the data itself which mainly arise from classification errors and errors in data acquisition. These uncertainties can be only be resolved by using higher resolution data with more training sites and better classification algorithms but creation of such products will require enormous time and resources. Data for Nebraska showed that there is a correlation between replaced grassland and planted corn; however this correlation decreases over time as biofuel production continued to rise (figure2). Demand for biofuel should have resulted in stronger correlation over time. This shows that grassland was already being replaced by corn even before the demand for biofuels increased. So the challenge is to differentiate between the normal and the induced change i.e. if grassland was being replaced by corn how does one differentiate replacement caused by corn grown for biofuel. There is a great deal of uncertainty between the relationship of biofuel growth and land use change. Though some studies have established strong causal relationship between these two based on model outputs and assumptions, analysis of available data shows that there no established relationship or established correlation between biofuel growth and land use change. Though there are some indications that biofuel growth has caused land use in random years there is no established trend or causal relationship between the two. 
More detailed studies with better data need to be done before a causal relationship can be firmly established.

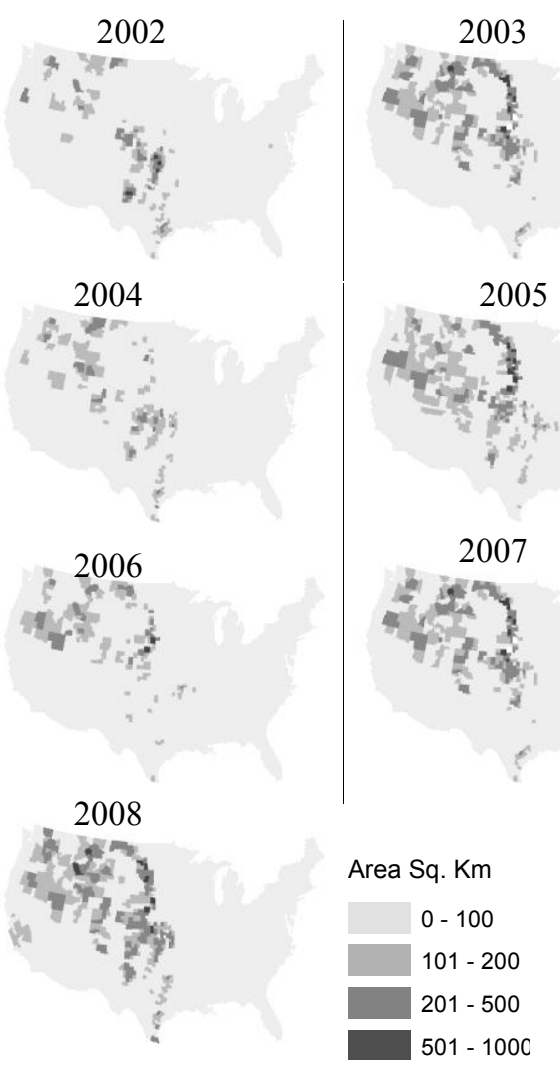

Figure 1-Spatial distribution of grassland converted to grassland for 2002-2008

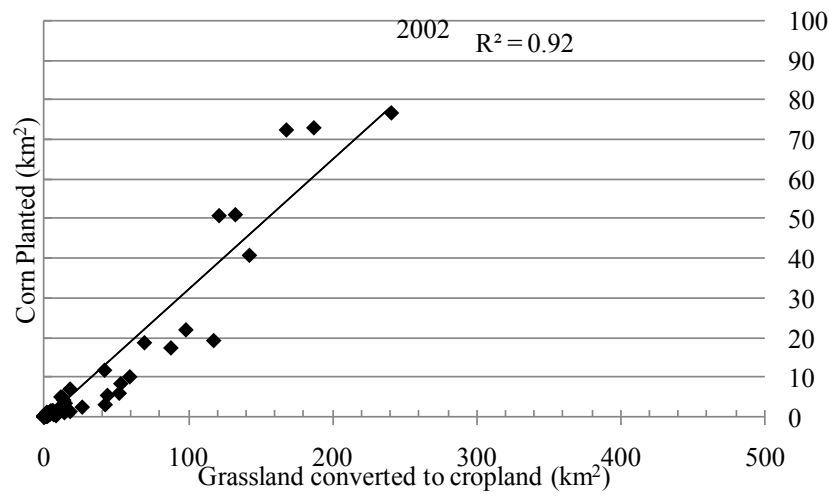

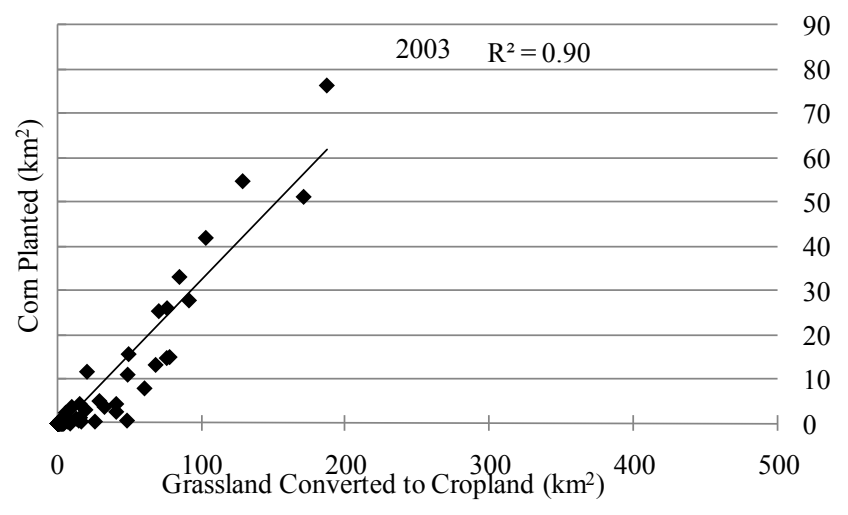
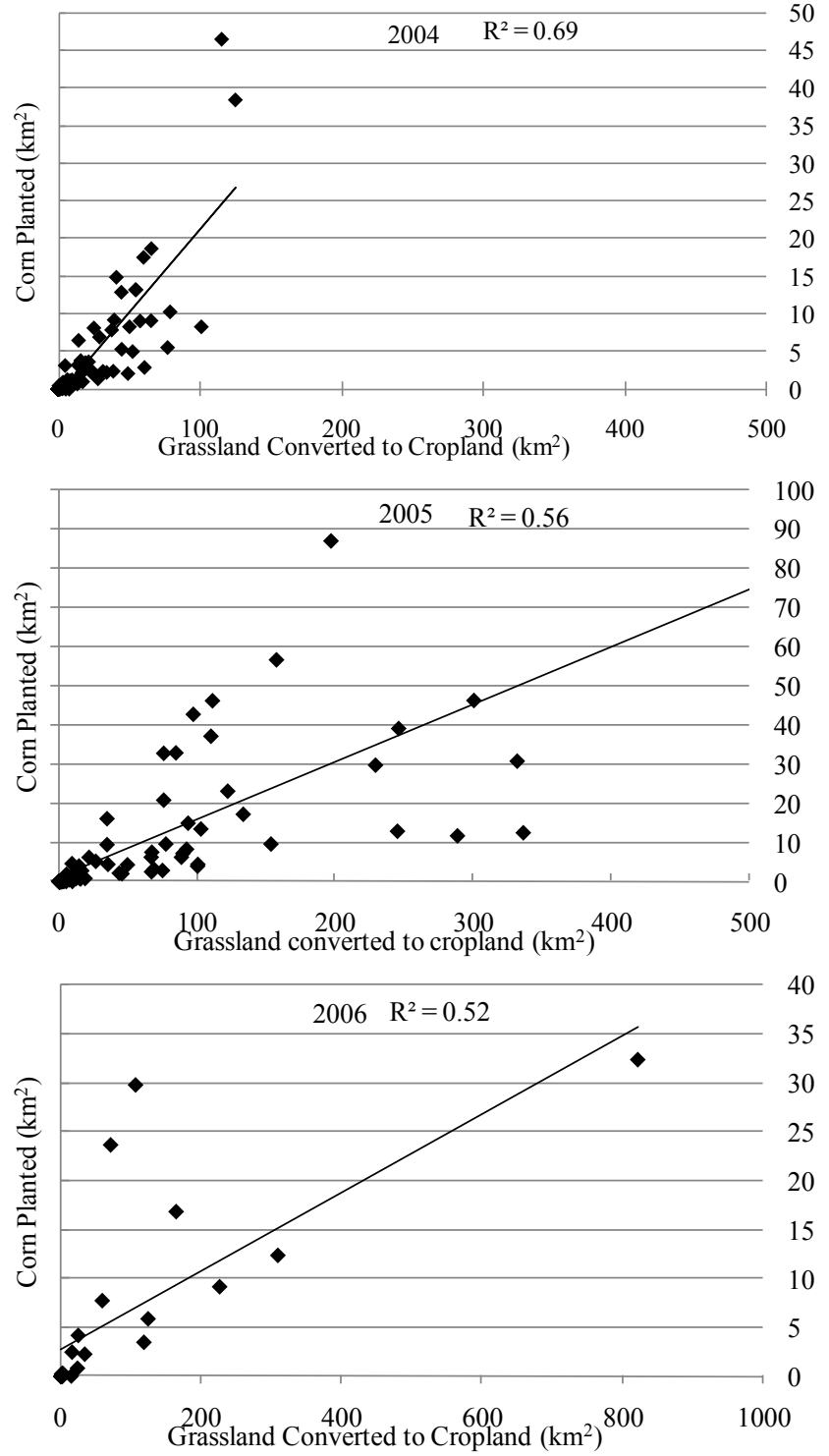


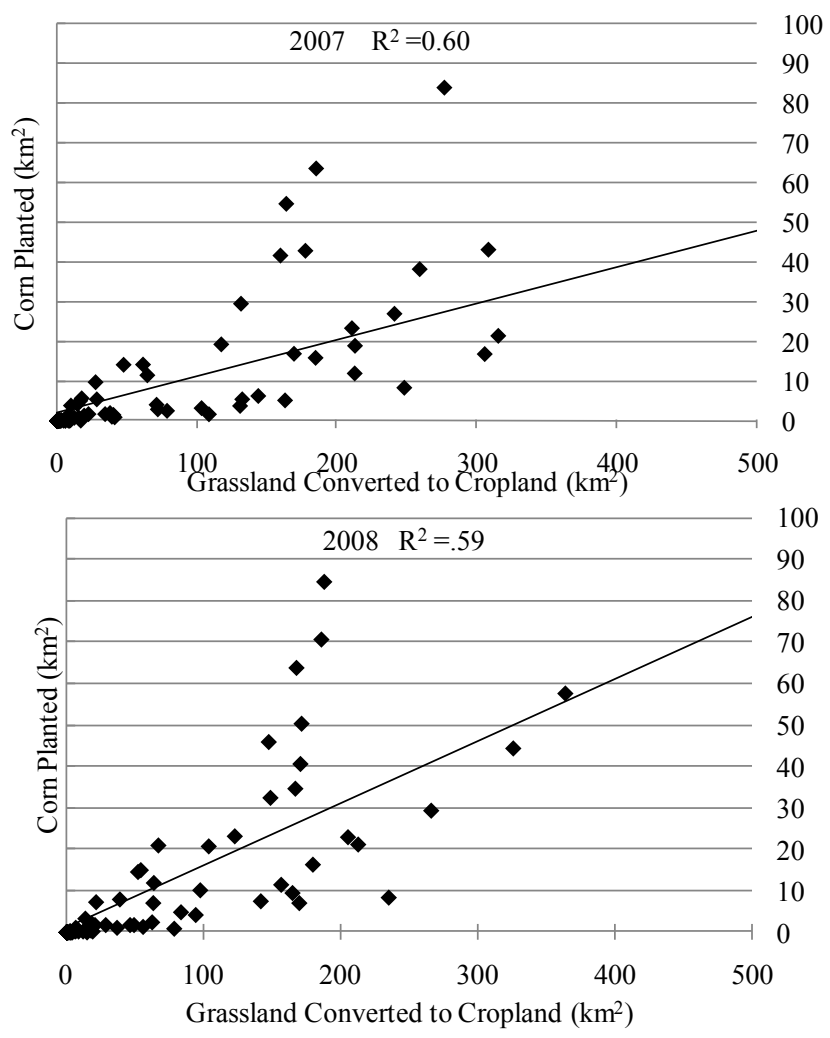

Figure 2- Scatterplot of corn planted versus grassland converted to cropland for all the 93 counties of Nebraska.

\section{REFERENCES}

[1] P.M.Vitousek et al., "Human Domination of Earth's Ecosystems" Science 277, pp 494-499,1007

[2] F.F.Lambin, et al., "The causes of land-use and land-cover change: moving beyond the myths", Global Environmental Change, 11(4), pp 261-269, 2001

[3] H.J. Geist and E.F. Lambin, "Proximate Causes and Underlying Driving Forces of Tropical Deforestation" BioScience pp 143-150,2002

[4] Fargione, J., Hill, J., Tilman, D., Polasky, S., Hawthorne, P., 2008. "Land Clearing and the Biofuel Carbon Debt", Science ,319, 1235-1238.

[5] J.Hill ,E. Nelson,D. Tilman, S. Polasky,D. Tiffany," Environmental, economic, and energetic costs and benefits of biodiesel and ethanol biofuels" Proceedings of the National Academy of Sciences ,pp 11206-11210,2006.

[6] Searchinger, T., Heimlich, R., Houghton, R.A., Dong, F.X., Elobeid, A., Fabiosa, J., Tokgoz, S., Hayes, D., Yu, T.H., 2." Use of US croplands for biofuels increases greenhouse gases through emissions from land-use change", Science 319, pp. 1238-1240,2008

[7] Lubowski, R.N., M. Vesterby, S. Bucholtz, A.

Baez, M.J. Roberts. 2006. Major uses of land in the United States. Economic Information Bulletin No. (EIB-14). USDA Economic Research Service, Washington DC,2006

[8] Ramankutty, N., and J. A. Foley,” Estimating historical changes in global land cover: Croplands from 1700 to 1992", Global Biogeochem. Cycles, 13(4), pp 997-1027,1999

[9] Friedl M, Sulla-Menashe D, Tan B, Schneider A, Ramankutty N, Sibley A and Huang X 2009 MODIS Collection 5 global land cover: algorithm refinements and characterization of new datasets, Remote Sensing of Environment, Volume 114, Issue 1, 15 January 2010, Pages 168-182,

[10] Rick Mueller, and M. Ozga, 2002, "Creating a Cropland Data Layer For an Entire State", Proceedings of the ACSM-ASPRS Conference, Washington DC (2002). 